\title{
Using the Fictitious Force to Judge the Stability of Pipe String is Wrong
}

\author{
Zifeng $\mathrm{Li}^{*}$
}

Petroleum Engineering, Institute of Yanshan University, Qinhuangdao 066004, China

\begin{abstract}
Pipes are under the trial of internal and external pressure of fluid in oil well drilling and production. Changes of internal and external pressure of fluid may affect equivalent axis force using for stability analysis of pipes in some cases. Errors in traditional mechanical model and fictitious force are discussed. Mechanical model representing true tubular conditions is established. Internal and external pressure of fluid and its changes have no effects on the stability of hanging pipes. Changes in internal and external pressure of fluid show effects on equivalent axis force and stability of pipes fixed at two ends. Equations for calculating equivalent axis force are established depending on constant axis strain. For pipes fixed at two ends, equivalent axis force decreases when internal pressure increases, equivalent axis force increases when external pressure increases; increase of internal pressure and decrease of external pressure may make equivalent axis force negative, even less than critical buckling force.
\end{abstract}

Keywords: Casing, tubing, external pressure, internal pressure, stability, buckling, fictitious force, equivalent axis force.

\section{INTRODUCTION}

All pipe strings in oil wells, such as drill string, casing string, tubing string and pumping rod string work under internal and external pressure. Internal and external pressures affect mechanical behavior of pipe strings, and sometimes, affect stability [1-4]. A Lubinski defined a fictitious force using energy method [1], and Chinese scholars introduced it to Chinese people [5-9], meanwhile used this force to judge stability conditions of pipe strings. However, is the mechanical model true? Is fictitious force really fictitious? Is the formula correct? Is the filed application effective? All of them are questioned $[10,11]$.

\section{MISTAKES IN TRADITIONAL THEORY}

\subsection{Traditional Theory}

Structural Stability Research Council of USA holds that the internal and external pressure on oil well pipes can cause the increase and decrease of pipe axis force, affecting the stability conditions. External pressure produces tension force in pipe strings. Internal pressure produces compressive force in pipe strings. A Lubinski defined this effect as fictitious force $[1,7,8]$

$$
F_{\mathrm{s}}=p_{\mathrm{o}} A_{\mathrm{o}}-p_{\mathrm{i}} A_{\mathrm{i}}
$$

where, $F_{\mathrm{s}}$ is the fictitious force, $p_{\mathrm{o}}$ is the external pressure, $A_{\mathrm{o}}$ is the area of external circle of pipe, $p_{\mathrm{i}}$ is the internal pressure and $A_{\mathrm{i}}$ is the area of internal circle of pipe.

Equation (1) shows the mechanical model in (Fig. 1) [8, 9]. There are top and bottom chambers in a pressure vessel. The pressure is $p$ in the top chamber. The pressure is $p_{\mathrm{o}}$ in the bottom chamber. There is an elastic tube, inner

*Address correspondence to this author at the Petroleum Engineering Institute, Yanshan University, Qinhuangdao 066004, China;

Tel: 86-335-8079211; Email: zfli@ysu.edu.cn radius $R_{\mathrm{i}}$, outer radius $R_{\mathrm{o}}$. There are two guiding columns and their radius is little smaller than $R_{\mathrm{i}}$, one at the top and the other at the bottom. The bottom end of the pipe touches the bottom of the bottom chamber. The top end of the pipe is in the top chamber. The pipe can slide along the top guiding column under action of pressure $p$. Energy method is used here.

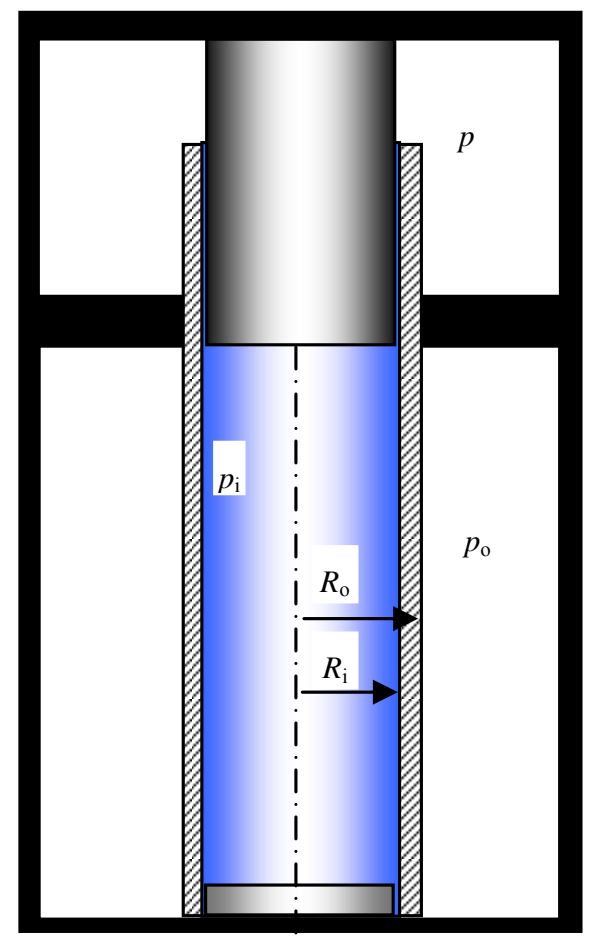

Fig. (1). Traditional mechanical model.

If there is a real axis force $F_{\mathrm{z}}$ in the section of pipes, then the effective axis force for pipe's stability calculation is [4]. 


$$
F_{\mathrm{b}}=F_{\mathrm{z}}+F_{\mathrm{s}}=F_{\mathrm{z}}+p_{\mathrm{o}} A_{\mathrm{o}}-p_{\mathrm{i}} A_{\mathrm{i}}
$$

where, $F_{\mathrm{b}}$ is the effective axis force.

Use $F_{\mathrm{b}}$ to identify the stability condition. If $F_{\mathrm{b}}>0$, then the pipe is stable. If $F_{\mathrm{b}}<0$, then the pipe is in buckling station.

\subsection{Mistakes}

The mechanical model with two guiding columns in (Fig. 1) is not true. In oil wells, the true mechanical model is shown in (Fig. 2), A for a pipe hanging vertically, $\mathrm{B}$ and $\mathrm{C}$ for a pipe fixed at two ends. For a pipe hanging freely, $F_{z}=0$, no matter how high the internal pressure is, the pipe can only expand both in length and in diameter, cannot buckle. If using equation (2) is applied to identify the stability condition, the pipe may be buckled. Thus, equation (1) and (2) are inapplicable. Equally, no matter how high the external pressure is, the pipe cannot buckle. For this reason, internal and external pressures themselves cannot cause the buckling of a hanging pipe.

\section{TRUE MECHANICAL MODEL AND EFFECTS OF INTERNAL AND EXTERNAL PRESSURE ON EQUIVALENT AXIS FORCE OF A DOUBLE ENDS FIXED PIPE}

For a double ends fixed pipe, both internal and external pressure cannot cause the buckling of a hanging pipe directly. The changes in internal and external pressure may cause equivalent axis force decrease, resulting pipe buckling.

In Fig. (2), A is a hanging pipe with internal pressure $p_{\mathrm{i}}$, external pressure $p_{\mathrm{o}}$, axis force $F_{\mathrm{z}}$ at the bottom, the equivalent axis force using for buckling analysis $F_{\mathrm{a}}=F_{\mathrm{z}}$. B is a hanging pipe with internal pressure $p_{\mathrm{i} 1}$, external pressure $p_{\mathrm{o} 1}$, axis force $F_{\mathrm{zl}}$ at the bottom, and it is fixed at the bottom after these loads are added, the equivalent axis force using for buckling analysis $F_{\mathrm{a} 1}=F_{\mathrm{z} 1}$. Due to the loads in B, internal pressure turns into $p_{\mathrm{i} 2}$, external pressure turns into $p_{\mathrm{o} 2}$, axis force keeps $F_{\mathrm{z} 1}$ at the bottom, as to $\mathrm{C}$, how to calculate axis force $F_{\mathrm{a} 2}$

In Fig. (2) A, axis stress, radial stress and tangential stress are [12]

$$
\left\{\begin{array}{l}
\sigma_{\mathrm{z}}=\frac{F_{\mathrm{z}}+p_{\mathrm{i}} A_{\mathrm{i}}-p_{\mathrm{o}} A_{\mathrm{o}}}{A}=\frac{F_{\mathrm{z}}+p_{\mathrm{i}} \pi R_{\mathrm{i}}^{2}-p_{\mathrm{o}} \pi R_{\mathrm{o}}^{2}}{\pi\left(R_{\mathrm{o}}^{2}-R_{\mathrm{i}}^{2}\right)} \\
\sigma_{\mathrm{r}}=\frac{p_{\mathrm{i}} R_{\mathrm{i}}^{2}-p_{\mathrm{o}} R_{\mathrm{o}}^{2}}{R_{\mathrm{o}}^{2}-R_{\mathrm{i}}^{2}}-\frac{\left(p_{\mathrm{i}}-p_{\mathrm{o}}\right) R_{\mathrm{i}}^{2} R_{\mathrm{o}}^{2}}{\left(R_{\mathrm{o}}^{2}-R_{\mathrm{i}}^{2}\right) r^{2}} \\
\sigma_{\dot{\mathrm{e}}}=\frac{p_{\mathrm{i}} R_{\mathrm{i}}^{2}-p_{\mathrm{o}} R_{\mathrm{o}}^{2}}{R_{\mathrm{o}}^{2}-R_{\mathrm{i}}^{2}}+\frac{\left(p_{\mathrm{i}}-p_{\mathrm{o}}\right) R_{\mathrm{i}}^{2} R_{\mathrm{o}}^{2}}{\left(R_{\mathrm{o}}^{2}-R_{\mathrm{i}}^{2}\right) r^{2}}
\end{array}\right.
$$

where, $\sigma_{\mathrm{z}}$ is the axis stress, $\sigma_{\mathrm{r}}$ is the radial stress, $\sigma_{\mathrm{e}}$ is the tangential stress, $r$ is the radius.

The axis strain

$\varepsilon_{z}-\frac{1}{E}\left[\sigma_{z}-\mu\left(\sigma_{\tau}+\sigma_{\mathrm{e}}\right)\right]-\frac{1}{E}\left[\frac{F_{z}+p_{1} \pi R_{1}^{2}-p_{0} \pi R_{0}^{2}}{\pi\left(R_{0}^{2}-R_{1}^{2}\right)}-2 \mu \frac{p_{1} R_{1}^{2}-p_{0} R_{0}^{2}}{R_{0}^{2}-R_{1}^{2}}\right]$

where, $E$ is the elastic module, $\mu$ is the Poisson's ratio.

In Fig. (2) $\mathbf{B}$ and $\mathbf{C}$, axis strains are equal

$$
\begin{aligned}
& \frac{F_{\mathrm{z} 1}+p_{\mathrm{i} 1} \pi R_{\mathrm{i}}^{2}-p_{\mathrm{o} 1} \pi R_{\mathrm{o}}^{2}}{\pi\left(R_{\mathrm{o}}^{2}-R_{\mathrm{i}}^{2}\right)}-2 \mu \frac{p_{\mathrm{i} 1} R_{\mathrm{i}}^{2}-p_{\mathrm{o} 1} R_{\mathrm{o}}^{2}}{R_{\mathrm{o}}^{2}-R_{\mathrm{i}}^{2}} \\
& =\frac{F_{\mathrm{a} 2}+p_{\mathrm{i} 2} \pi R_{\mathrm{i}}^{2}-p_{\mathrm{o} 2} \pi R_{\mathrm{o}}^{2}}{\pi\left(R_{\mathrm{o}}^{2}-R_{\mathrm{i}}^{2}\right)}-2 \mu \frac{p_{\mathrm{i} 2} R_{\mathrm{i}}^{2}-p_{\mathrm{o} 2} R_{\mathrm{o}}^{2}}{R_{\mathrm{o}}^{2}-R_{\mathrm{i}}^{2}}
\end{aligned}
$$

then

$$
\begin{aligned}
F_{\mathrm{a} 2} & =F_{\mathrm{z} 1}+\pi(1-2 \mu)\left[\left(p_{\mathrm{i} 1}-p_{\mathrm{i} 2}\right) R_{\mathrm{i}}^{2}-\left(p_{\mathrm{o} 1}-p_{\mathrm{o} 2}\right) R_{\mathrm{o}}^{2}\right] \\
& =F_{\mathrm{z} 1}+(1-2 \mu)\left[\left(p_{\mathrm{i} 1}-p_{\mathrm{i} 2}\right) A_{\mathrm{i}}-\left(p_{\mathrm{o} 1}-p_{\mathrm{o} 2}\right) A_{\mathrm{o}}\right]
\end{aligned}
$$

If internal pressure increases and/or external pressure decrease, equivalent axis force may be negative, even less than critical buckling load, resulting buckling.

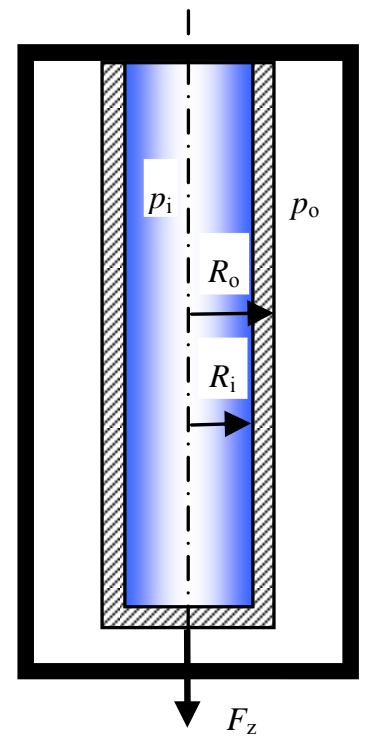

A

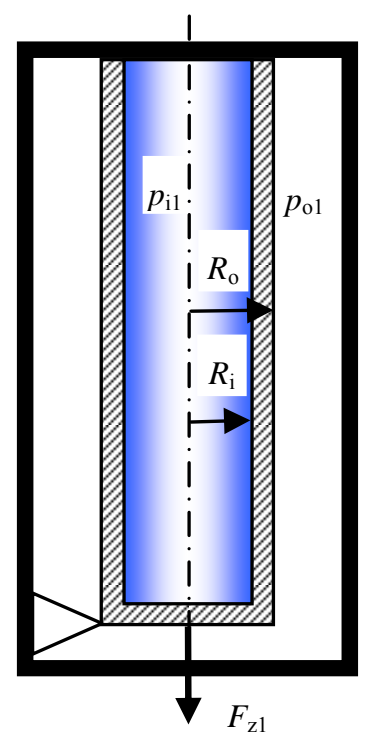

B

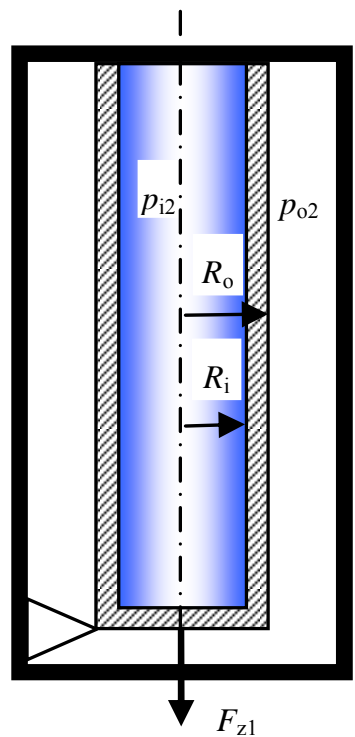

$\mathrm{C}$

Fig. (2). True mechanical model. 
For a pipe fixed at two ends, it is the changes of internal and external pressures, not the internal and external pressures themselves, changing the stability conditions.

The change of axis force, $(1-2 \mu)\left[\left(p_{\mathrm{i} 1}-p_{\mathrm{i} 2}\right) A_{\mathrm{i}}-\left(p_{\mathrm{o} 1}-p_{\mathrm{o} 2}\right) A_{\mathrm{o}}\right]$, is the force acting on restriction such as cement sheath or anchor, due to the restriction, preventing axis expansion.

It can be verified that equation (6) is suitable for double end closed pipe. For column, $A_{\mathrm{i}}=0$, equation (6) is also suitable. For double end opened pipe, $p_{\mathrm{i} 1}=p_{\mathrm{o} 1}, p_{\mathrm{i} 2}=p_{\mathrm{o} 2}$, equation (6) is still applicable.

\section{CONCLUSIONS}

(1) Fictitious force used for pipe stability calculation is inapplicable.

(2) Internal and external pressure cannot cause buckling of a hanging pipe string.

(3) Internal and external pressures themselves can not cause buckling of a double ends fixed pipe string. For a double ends fixed pipe string, the changes of internal and external pressure can affect its stability. Equivalent axis force is a function of initial axis force, Poisson's ratio of pipe material, change of internal pressure, change of external pressure, area of internal circle of pipe and area of external circle of pipe.

(4) For a double ends fixed pipe string, the increase in internal pressure decreases stability, the increase in external pressure increases stability.

\section{CONFLICT OF INTEREST}

The author(s) confirm that this article content has no conflicts of interest.

\section{ACKNOWLEDGEMENT}

The paper is supported by NSFC No. 51244004 and 51374183.

\section{NOMENCLATURE}

$A_{\mathrm{i}} \quad=$ Area of internal circle of pipe

$A_{\mathrm{o}} \quad=$ Area of external circle of pipe

$E \quad=$ Elastic module

$F_{\mathrm{a}} \quad=$ Equivalent axis force using for buckling analysis

$F_{\mathrm{a} 1}=$ Equivalent axis force using for buckling analysis before fixed at the bottom

$F_{\mathrm{a} 2}=$ Equivalent axis force using for buckling analysis after fixed at the bottom

$F_{\mathrm{b}} \quad=$ Effective axis force

$F_{\mathrm{s}} \quad=$ Fictitious force
$F_{\mathrm{z}} \quad=$ Real axis force

$F_{\mathrm{z} 1}=$ Real axis force at the bottom

$p=$ Pressure in the top chamber

$p_{\mathrm{i}}=$ Internal pressure

$p_{\mathrm{i} 1}=$ Internal pressure before fixed at the bottom

$p_{\mathrm{i} 2}=$ Internal pressure after fixed at the bottom

$p_{\mathrm{o}}=$ External pressure

$p_{01}=$ External pressure before fixed at the bottom

$p_{02}=$ External pressure after fixed at the bottom

$r \quad=$ Radius

$R_{\mathrm{i}} \quad=$ Inner radius

$R_{\mathrm{o}} \quad=$ Outer radius

$\varepsilon_{\mathrm{z}}=$ Axis strain

$\mu=$ Poisson's ratio

$\sigma_{\mathrm{r}} \quad=$ Radial stress

$\sigma_{\mathrm{z}}=$ Axis stress

$\sigma_{\grave{\mathrm{e}}}=$ Tangential stress

SI unit is used.

\section{REFERENCES}

[1] A. Lubinski, and K. Blenkarn, "Buckling of tubing in pumping wells, its effects and means for controlling it", Transcription of $A S M E$, vol. 210, pp. 73-88, 1957.

[2] A. Lubinski, Influence of tension and compression on straight and buckling of tubular goods in oil wells. API Bulletin Proc., $31^{\text {st }}$ Annual Meetings Developments in petroleum engineering vol. 1. Stability of tubulars, 1987.

[3] Z. Li, X. Ma, and W. Huang, "Static stability of pipe string in oil and gas wells", Engineering Mechanics, vol. 14, no. 1, pp. 17-25, 1997. (In Chinese)

[4] Z. Li, and J. Li, "Fundamental equations for dynamic analysis of rod and pipe string in oil-gas wells and application in static buckling analysis", Journal of Canadian Petroleum Technology, vol. 41, no. 5, pp. 44-53, 2002.

[5] N. Zhang, and K. Yuan, " Effects of common fluid pressures on oil well pipes", Oil Drilling \& Production Technology, vol. 4, no. 5, pp. 73-84, 1982. (In Chinese)

[6] J. Wu, "Buckling analysis of casing in uncementing section", Oil Drilling \& Production Technology, vol. 9, no. 3, pp. 7-17, 1987. (In Chinese)

[7] J. Hao, and W. Gong, Casing Strength Design and Calculation. Petroleum Industry Press: Beijing, 1987. (In Chinese)

[8] W. Gong, "Buckling of pipe under hydraulic pressure", Oil Drilling \& Production Technology, vol. 10, no. 3, pp. 11-22, 1988. (In Chinese)

[9] Z. Han, Oil Well String Mechanics under Hydraulic Environment. Petroleum Industry Press: Beijing, 1987. (In Chinese)

[10] X. Cui, H. Zhang, and Z. Song, "A research on casing string stability of oil well”, Acta Petrolei Sinica, vol. 19, no. 1, pp. 114-118, 1998. (In Chinese) 
[11] H. Shu, W. Luo, and Y. He, "Critical buckling load of casing string subjected to internal and external liquid pressure", Oil Field Equipment, vol. 31, no. 2, pp. 19- 22, 2002. (In Chinese)
[12] Z. Li, Tubular Mechanics in Oil-Gas Wells and Its Applications. Petroleum Industry Press: Beijing, 2008. (In Chinese)

Received: August 20,2013

Revised: September 16, 2013

Accepted: September 17, 2013

(C) Zifeng Li; Licensee Bentham Open.

This is an open access article licensed under the terms of the Creative Commons Attribution Non-Commercial License (http://creativecommons.org/licenses/by-nc/3.0/) which permits unrestricted, non-commercial use, distribution and reproduction in any medium, provided the work is properly cited. 